\title{
A CROSSROADS IN THE FIGHT AGAINST HUMAN TRAFFICKING? LET'S TAKE THE STRUCTURAL ROUTE: A RESPONSE TO JANIE CHUANG
}

\author{
Karen E. Bravo*
}

Even ten years ago, the phrase "human trafficking" might have evoked blank stares in many circles. Today, the existence of a contemporary trade in human beings has blossomed fully into public awareness. Discussion of and expositions about human trafficking appear not only in sensationalist media reports, but also in many other arenas, such as film dramas, documentaries, books and articles by scholars from a variety of disciplines, activist NGO websites, and legislative chambers across the globe.

However, some legal scholars as well as other scholars in the human trafficking sphere admit to a growing unease. Why? There is the sense that the label is a mushrooming monster that encompasses or swallows up all forms of human exploitation, identifies or creates stereotypical bad guys and innocent victims, and yet leaves relatively untouched the root causes of the exploitation.

Arguing that anti-human trafficking laws are at a crossroads, Janie Chuang supports a labor infused structural approach. ${ }^{1}$ While I share her focus on the structural foundations of human trafficking, I assert the need to question and go beyond deeply held assumptions that underlie even the mechanisms that Chuang views as potential avenues for addressing these foundations. I also explore my opinion that, although she identifies some of the harms that stem from the exploitative use of the term "slavery" and offers a critique of its indiscriminate use throughout the dominant contemporary anti-human trafficking discourse, Chuang does not fully address the consequences of its rash and over-expansive use.

Chuang's excellent article offers a persuasive account and interpretation of the developments and evolution of anti-human trafficking laws. She presents a rich macro explanation for the doctrinal, discursive and implementation developments in the field that takes account of the multifaceted and multi-threaded influence of politics and power, and of the financial and rhetorical influence of moral entrepreneurs and well-funded donors. Chuang diagnoses "exploitation creep" within the spheres of anti-human trafficking laws and advocacy work: the conflation of the "human trafficking" and "slavery" definitions, and the ways of talking about slavery and human trafficking, such that all coerced labor is "human trafficking" and all "human trafficking" is "slavery." 2 Chuang explains her view that "maintaining the core of what 'trafficking' was intended to cover requires staving off not only the risk of under-inclusiveness that the slavery claim promotes, but also of over-inclusiveness that increased attention to exploitation writ large might inspire."3

* Professor of Law and Associate Dean for Graduate Studies and International Affairs, Indiana University Robert H. McKinney School of Law. Thanks to Lea Shaver for comments on an earlier draft, and to Karen Knop for her excellent editing.

Originally published online 11 June 2015.

${ }^{1}$ Janie Chuang, Exploitation Creep and the Unmaking of Human Trafficking Law, 108 AJIL 610 (2014).

${ }^{2}$ For example, Chuang notes that: "What was once a peripheral tool to garner popular support for the anti-trafficking cause is nowby U.S. government design— the central framing device: recasting forced labor and trafficking as nothing short of slavery.” $\underline{I d}$. at 20.

${ }^{3} \underline{I d}$. at 33 . 
Chuang identifies two entry points that created the opportunity for exploitation creep: the intentionally vague definition agreed to in the influential UN Trafficking Protocol, ${ }^{4}$ and the embrace and exploitation of the use of the term "slavery" and the slavery comparison by the United States and civil society anti-trafficking moral entrepreneurs. ${ }^{5}$ For Chuang, the consequences of exploitation creep are mixed, leading first, unanticipated by its proponents, to a new, enriched, and more mature understanding of human trafficking, pursuant to which the targeted exploitation more fully includes labor, as well as sexual, exploitation; and, second, to the dilution of the meaning of "human trafficking," such that the term appears to include all forms of exploitation and the use of the term adheres to no broadly accepted definition.

As a consequence, according to Chuang, human trafficking efforts are at a crossroads. Either human trafficking law and advocacy, enriched with the unanticipated labor rights perspective, will adopt a more structural approach that incorporates more robust labor protection or they will be rendered ineffective by continued reliance on the dominant law enforcement-criminalization model. Named "modern-day-slavery abolitionism" or "MDS abolitionism" by Chuang, this model consists of an over-emphasis on the identification and prosecution of individual wrongdoer bad guys and the identification and "rescue" of victims.

Denouncing the continued ineffectiveness of this approach, ${ }^{7}$ Chuang unequivocally supports the pursuit of the more structural line of attack that is facilitated by the incorporation of a labor rights perspective. In her view, this structural direction will best capture the benefits and avoid the risks of exploitation creep.

I agree with Chuang's diagnosis of the state of anti-human trafficking law and the current crossroads with respect to the adoption of strategies. However, in my view, we must go further with respect to (1) the assessment of the complex effects of the use of the term "slavery" and the attempts by MDS abolitionists to harness the word's impact to drive forward their perceptions and agenda; and (2) the scope of the structural inquiry and targeting afforded by the unlooked-for incorporation of the labor rights perspective.

\section{Slavery's Utility}

Words are powerful, directing our thoughts among a variety of alternative pathways. Chuang flags the issue of the expanded and normalized use of slavery to describe the exploitation labeled as human trafficking and the consequent potential to undermine victim protection: The over-inclusive use of the term draws broad societal support and attention to anti-human trafficking efforts, while at the same time dissipating the definitional rigor of the legal terms "slavery" and "human trafficking.". Further, trafficked persons who seek redress are unable to reach the standards imposed by mental images of the extreme conditions of historical slavery and are thus deprived of relief. As a result, the original targets of the international and domestic anti-trafficking efforts continue unaddressed and unresolved.

I contend that the inapt use of the term "slavery" is even more problematic than Chuang acknowledges because, ironically, it distracts from the structural causes and foundations of the contemporary trade in human beings. Reconnected with their structural history, however, the term "slavery" and a slavery-imbued analysis of

${ }^{4}$ Protocol to Prevent, Suppress and Punish Trafficking in Persons, Especially Women and Children, Supplementing the United Nations Convention Against Transnational Organized Crime, GA Res. 55/25 (Nov. 15, 2000), art. 3 [hereinafter U.N. Trafficking Protocol]. According to Chuang: "For the sake of achieving consensus, however, the Protocol drafters left key aspects of the legal definition intentionally vague." $\underline{I d}$. at 2 .

5 See Karen E. Bravo, Exploring the Analogy between Modern Trafficking in Humans and the Trans-Atlantic Slave Trade, 25 B.U. INT’L L.J. 207 (2007) [hereinafter Bravo, Exploring the Analogy] and Karen E. Bravo, The Role of the Trans-Atlantic Slave Trade in Contemporary Anti-Trafficking Discourse, 9 SEATTLE J. FOR SOC. JUST. 555 (2011) (each challenging the superficiality and emotional exploitation of these uses).

${ }^{6}$ I flagged the potential danger of "neo-abolitionism" in Bravo, Exploring the Analogy, supra note 5, at 240-43.

${ }^{7}$ Chuang cites the limited number of prosecutions worldwide and the "over 20 million victims yet to be identified." Chuang, supra note 1 , at 4 . (These numbers apply to 2013 alone.) 
human trafficking offer more nuanced and fruitful analytical perspectives on anti-human trafficking efforts. Among the dangers of MDS abolitionism is that, although it has roused, and attempted to benefit from, the visceral reactions and resolve of a significant swath of society, the term "slavery" is a two-edged sword. It channels the imagination and focus of the public and the unwary anti-trafficking campaigner due not only to the deeply felt reactions evoked by images of and references to trans-Atlantic slavery, but also to the willful and widespread ignorance of historic (including trans-Atlantic) slavery's legal, political, economic, and other structural foundations and enforcement supports. As a result, they perceive and target individual bad acts and actors, but fail to identify or target the comparable contemporary structural causes and supports of today's trade in human beings.

The rhetoric and perceptions of the law's abolition of chattel slavery and of the ius cogens norm enshrined in the international instruments that effect chattel slavery's worldwide legal prohibition hide the continued role of laws and legal institutions in creating slavery-like forms of exploitation. In addition, the MDS abolitionists employ a deracinated, yet omni-racinated depiction of the exploitation which harnesses the public's outrage that the cruel exploitation of trans-Atlantic slavery should be revisited on individuals and groups in our lifetimes, while it simultaneously avoids connecting the vulnerability to trafficking and exploitation of some populations to the global legacy of racial exploitation. Portrayals and analyses of human trafficking largely avoid the reality of the vulnerability to exploitation that derives from historic slavery, colonization, and the global racial subordination and "other"-ization of blackness. The victims depicted are, instead, an omni-racial rainbow of races, ethnicities, and colors, illustrating the ethos of "anyone can be trafficked, because the bad guys are everywhere." 8 Such depictions remove the role of ethnicity and race in entrenching the subordinated status of some populations and thus hide the race-based structural foundations of exploitation. Yet, the powerful emotional reactions are tied to the images of historic slavery, and spring from the guilt and shame held in the public consciousness. Curiously, then, the invocation of "slavery" - a centuries-long system of exploitation created and enforced through and by laws and legal institutions as well as economic and political structures-and of today's domestic and international legal prohibitions of slavery serve to mask the comparable contemporary structural foundations and enforcement mechanisms.

Furthermore, states play an integral role in demarcating and enforcing today's sources and preconditions of exploitability. ${ }^{9}$ Through the domestic and international legal abolition and prohibition of slavery, states give the impression that they are fully engaged in combatting these forms of exploitation. This is far from true. For example, their adoption of laws and policies in other, seemingly unrelated spheres such as immigration and trade liberalization helps to establish and police the conditions that give rise to the contemporary forms of exploitation labeled "modern day slavery."10

Invoking the illegality of slavery today leads to default assumptions that existing legal, political, and economic structures are innocent or non-complicit. Compared to the extremes of human trafficking, the racial disparities and rationales for inequality embedded within existing structures, both within and across states, seem a less exploitative arrangement. The status quo racialized subordination and exploitation thus escape notice as an appropriate target for anti-human trafficking efforts.

Identifying a new bogeyman-i.e., modern day slavery—highlights the role of emblematic bad guys, transgressors against the ius cogens norm against enslavement. The focus on their identification and punishment

${ }^{8}$ Yes, but who is more likely to be trafficked, based on structural vulnerabilities?

9 See Bravo, Exploring the Analogy, supra note 4, at 292. ("States may be said to be complicit in creating and enforcing the vulnerability of some populations. That accusation is not negated by the mobilization of state resources against human trafficking.")

10 See Karen E. Bravo, Interrogating the State's Roles in Human Trafficking, 25 IND. INT'L \& COMP. L. REv. 9 (2014) (explaining that states play a role in facilitating human trafficking). 
creates the ideal excuse for inaction both for the powerful and wealthy (largely content with the current unequal allocation of resources) and for the average consumer and moral warrior. We would much rather not disrupt existing modalities of wealth and resource allocation, which would potentially unsettle our own, relatively privileged mundane lives in order to address the deeper structural causes of vulnerability to human trafficking.

\section{A Deeper Structural Analysis}

In light of the identification of the structural foundations of historic slavery and human trafficking, Chuang's structural prescription does not go far enough in acknowledging and targeting the scope and nature of those foundations. Nor does she map their relationships to our everyday lives and to the economic and other policies of state actors, and the ways in which these policies intersect to give rise to the conditions that are the seedbed of human trafficking.

At this crossroads in the anti-human trafficking efforts, addressing the deeper underlying inequities of laws and policies that foster or permit this type of exploitation requires anti-human trafficking efforts to target more than the enhancement and enforcement of labor rights-protective mechanisms. They must include confronting the challenging question of whether states' continued monopoly on the sanctioned transborder movement of humans itself creates and maintains structural vulnerability to human trafficking. ${ }^{11}$

Chuang approves of the labor rights-infused methodologies fostered by the broader recognition of labor trafficking, including labor market regulation, particularly fraudulent or deceptive recruitment of (migrant) workers, as well as of "growing efforts to regulate labor supply chains, and target fraudulent foreign labor recruitment and prevent forced labor by government contractors and subcontractors." 12 A more structural approach that recognizes the role of labor laws in facilitating labor exploitation and trafficking is a step in the right direction, but does not go far enough. We need a more expansive approach that recognizes and addresses the place of immigration and human mobility in facilitating human trafficking. ${ }^{13}$ In the context of a globalized and globalizing human econo-sphere, the roles of international economic, trade, and border protection policies must be explicitly addressed.

I propose both a more expansive structural approach to decreasing the immigration-related vulnerability of would-be mobile humans, as well as a reexamination of the relationship between humans and their states. This would require recognizing the competition between labor and capital, and the reality that labor lacks the resources necessary to negotiate or compete with capital as an equal. The influential funder-founders of whom Chuang writes, beneficiaries of the contemporary economic, political, and legal structures, show no interest in reframing the traditional balance between labor and capital. Their brand of "venture philanthropy" identifies and punishes the "bad guys" whose methods of exploitation stand out from the normalized yet inequitable status quo. The solution proffered by funder-founders targets exploitation that goes beyond the legally created and

${ }^{11}$ Karen E. Bravo, Free Labor! Toward a Labor Liberalization Solution for Modern Trafficking in Humans, 18 TRANSNAT'L L. \& CONTEMP. PRoBs. 545, 548 (2009) [hereinafter, Bravo, Free Labor!]:

Modern trafficking in humans flourishes within four systemic tensions: (1) the gaps between the rhetoric and reality of trade liberalization undertaken thus far through multilateral and regional international instruments; (2) the gap between the conceptualization of humans as rights-bearing persons and as economic actors-both consumers and labor (an economic input or commodity); (3) the tension between the transnationalization unleashed by trade liberalization and Westphalian concepts of statehood; and (4) the tension between the recognition and enforcement of human rights (and individual personhood) and state sovereignty and control over constituent population and territory.

${ }^{12}$ Chuang, supra note 1 , at 36.

13 See Bravo, Free Labor!, supra note 11. 
sanctioned ones on which they and their wealth depend. Structurally-based anti-human trafficking methodologies which might target the foundations of the funder-founders' economic standing would necessarily encounter resistance from them.

Human trafficking is not an aberration-it is the product of a distorted market. It responds logically to global market forces and is deeply intertwined with legal markets in labor, goods, and services. The international labor market, which includes human trafficking, is disrupted by the collision of the contemporary trade liberalization project with increased nation-state enforcement of domestic immigration laws and militarization of nation state borders. On the one hand, contemporary trade liberalization rejects the inclusion of labor as a transnationally mobile autonomous economic unit. On the other hand, trade liberalization and global economic forces impose mobility on human labor in response to economic incentives and disincentives.

The emphasis on cheapness and efficiency, and on increasing returns and cheaper inputs has led, at some extremes, to the commodification of humans in their capacities as providers of labor, as trade objects, or as goods. The preconditions for human trafficking may spring, as well, from the intersection of the conceptualization of labor as purely a commodity ${ }^{14}$ and the belief that capital owes very little to labor.

My earlier challenge still stands:

The application of a global economic and trade-based analysis to the problem of trafficking clarifies the necessity of devoting more attention, thought, and study to the economic impact on human trafficking by the border enforcement and immigration barriers between labor-rich and labor-poor economies. These barriers force would-be immigrants who are responding to market forces to contract with smuggler-traffickers or corrupt officials in order to make transborder journeys in search of viable economic activity. Labor-rich economies with high unemployment and underemployment rates have high rates of poverty and desperation. These factors can lead to devaluation of human life and to the sale of men, women and children. ${ }^{15}$

Such a structural inquiry should also encourage challenge to state structures and borders. ${ }^{16}$

A real examination of the structural foundations of human trafficking would require grappling with antiimmigrant and border protection policies and their effects on economic, as well as political, refugees. ${ }^{17}$ It would demand the recognition of the role of economic development policies of resource-challenged states which facilitate the export of their citizens as exploited labor in wealthier states. ${ }^{18}$ It would encourage the corporate titan and the cash-strapped consumer alike to reckon the true cost of the "cheap" goods produced in low-wage states.

Chuang has produced a clear-eyed exposition of how anti-human trafficking efforts arrived at this crossroads. Do we have the courage to perform the deeper structural analysis and reform methodologies required to truly combat the contemporary trade in human beings?

${ }^{14}$ Evidence of this view includes references to "human capital" as a fungible asset which is deployed in production activities at the discretion of states and the owners of capital.

15 See Bravo, Free Labor!, supra note 11, at 553.

16 See Bravo, supra note 10.

${ }^{17}$ Examples include the African migrants who cross the Mediterranean in leaky boats and the children who flee to the United States in dread of gang-related violence.

18 The governments of the Philippines and Pakistan, for example actively assist their nationals in finding work in the Gulf States. Once they are there, their states are unable to protect them from many of the worst types of abuse. 